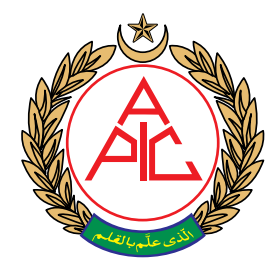

'[kvtamn68@gmail.com] \{ORCID:0000-0002-38416509\}

${ }^{2}[\mathrm{dr}$.armaanjeetsingh@gmail. com]

${ }^{3}$ [drrajaiims86@gmail.com] [dksbhu@gmail.com]

Department

Anesthesiology, Institute of Medical Sciences, Banaras Hindu University (IMS-BHU), Varanasi, Uttar Pradesh 221005, India

Correspondence: Dr. Rajesh Kumar Meena, Department of Anesthesiology, Institute of Medical Sciences, Banaras Hindu University (IMS-BHU), Aurobindo Colony, Banaras Hindu University Campus, Varanasi, Uttar Pradesh 221005, India.

E-mail:

drrajaiims86@gmail.com

Phone: 09643975465

Mobile: 919643975465

Received: 19 December

2019

Reviewed: 3 February 2020

Revised: 5 February 2020

Accepted: 5 March 2020

\section{Comparison of two doses of magnesium sulphate as sedative during awake fiberoptic intubation for patients undergoing maxillofacial surgery: A prospective RCT}

\author{
Kavita Meena ${ }^{1}$, Armaanjeet Singh ${ }^{2}$, Rajesh Kumar Meena ${ }^{3}$, \\ Dinesh Kumar Singh ${ }^{4}$
}

\section{ABSTRACT}

Background and objectives: Awake fiberoptic intubation (AFI) is the technique of choice for anticipated difficult intubation via nasal/oral route depending on the type of surgery. Various anesthetic techniques have been used to facilitate AFI, including regional anesthesia, topical anesthesia and sedation. There are few studies regarding the use of magnesium sulphate for this purpose. The aim of our study was to find the efficacy of magnesium sulphate as sedative in patients with maxillofacial trauma undergoing AFI and to establish the dose that provides better sedation.

Methodology: 80 patients with maxillofacial trauma scheduled to undergo open reduction and internal fixation were included in this randomized control trial. The patients were randomly divided into two groups. Group $\mathrm{M} 1$ received inj $\mathrm{MgSO}_{4} 30$ $\mathrm{mg} / \mathrm{kg}$ in $100 \mathrm{~mL} \mathrm{NS}$ and Group M2 received inj $\mathrm{MgSO}_{4} 45 \mathrm{mg} / \mathrm{kg}$ in $100 \mathrm{~mL} \mathrm{NS}$ over 10-15 min before surgery. Sedation was assessed using Ramsay Sedation Score.

Result: The sedation scores were found to be higher in Group M2 as compared to Group M1, which was statistically significant $(p<0.006)$. On comparison of hemodynamic parameters before and after intubation, more blunting of hemodynamic response seen with $45 \mathrm{mg} / \mathrm{kg} \mathrm{MgSO}_{4}$.

Conclusion: Magnesium sulphate provides good sedation for awake fiberoptic intubation in patients with maxillofacial trauma, and a dose of $45 \mathrm{mg} / \mathrm{kg}$ of magnesium sulphate provides deeper sedation as compared to $30 \mathrm{mg} / \mathrm{kg}$.

Key words: Difficult airway; Awake fibreoptic intubation; Magnesium sulphate; Hemodynamics

Citation: Meena K, Singh A, Meena RK, Singh DK. Comparison of two doses of magnesium sulphate as sedative during awake fiberoptic intubation for patients undergoing maxillofacial surgery: A prospective RCT. Anaesth. Pain intensive care 2020;24(2): 175-182

DOI: https://doi.org/10.35975/apic.v24i2.1254

\section{INTRODUCTION}

Maxillofacial surgeries are challenging for anesthesiologists due to profuse bleeding, facial edema, restricted mouth opening and other airway complications. Awake fiberoptic intubation (AFI) is the technique of choice for these cases via nasal/oral route depending on the type of surgery. ${ }^{1}$ 


\section{Comparison of two doses of magnesium sulphate as sedative}

There is reduced risk of aspiration with AFI, since the protective reflexes of the airway are maintained until just before an endotracheal tube is passed into the trachea. A nasal cannula can be used to deliver oxygen during sedation and intubation to prevent hypoxia.

Various techniques have been used to facilitate AFI, including regional anesthesia, topical anesthesia and sedation. Sedative medications decrease anxiety, ensuring patient's cooperation and a patent airway with adequate oxygenation and ventilation. Patient's response to fiberoptic scope advancement and tracheal intubation is blunted.

Numerous sedative drugs, either alone or in combination, have been used as an adjunct to AFI. Benzodiazepines together with opioids can achieve adequate patient comfort during intubation and sedation. Opioids like morphine or fentanyl provide analgesia and depress laryngeal reflexes. However, they are associated with respiratory depression. Other pharmacological agents include midazolam, fentanyl, dexmedetomidine and ${ }^{2}$ magnesium sulphate.

Magnesium plays an important role in a multitude of physiologic processes. Since the pioneer study of magnesium sulphate in clinical anesthesia in 1996, the drug has piqued interest in the field of anesthesia and pain medicine. Magnesium is the fourth commonest cation in a human body. It has a key role in a variety of physiologic processes. Among the numerous actions of magnesium, the blockade of calcium channels and N-methyl-D-aspartate (NMDA) receptor is significant in anesthesia. Magnesium sulphate has been used in preeclampsia patients to prevent seizure. It is also used for the treatment of arrhythmia, asthma, and as an anesthetic adjunct in patients undergoing surgery for pheochromocytoma and laparoscopic cholecystectomy.,

There is scarce literature regarding the use of magnesium sulphate as a sedative for AFI. In this study we aim to find the efficacy of magnesium sulphate as sedative in patients with maxillofacial trauma undergoing AFI and to compare two different doses of the medication.

\section{METHODOLOGY}

This study was conducted in the department of Anesthesiology, Institute of Medical Sciences, Banaras Hindu University, Varanasi, after obtaining the ethical committee approval. Written informed consent was obtained from all patients. 80 patients with maxillofacial trauma, scheduled to undergo open reduction and internal fixation (ORIF), were enrolled in this prospective randomized controlled study. Patients aged 18 to 50 years were included. Patients with lack of consent, previous allergic reaction to $\mathrm{MgSO}_{4}$, co-morbidity, coagulopathy, cervical spine trauma, neurological deficit and pregnancy were excluded from the study. The patients were divided into two groups using a list of random numbers, generated by a sealed envelope system.

All patients underwent a detailed pre-anesthetic evaluation with all the relevant investigations. They were kept nil per oral according to the recommended guidelines. They were premedicated with tab. alprazolam $0.25 \mathrm{mg}$, tab. ranitidine $150 \mathrm{mg}$ and tab. metoclopramide 10 $\mathrm{mg}$ the night before surgery and $2 \mathrm{~h}$ before intubation with 1-2 sips of water. An intravenous line was secured with an 18G IV cannula and an infusion was started using Ringer Lactate solution. Patients were administered $\mathrm{MgSO}_{4}(30 \mathrm{mg} / \mathrm{kg}$ for Group M1 and $45 \mathrm{mg} / \mathrm{kg}$ for Group M2) in $100 \mathrm{~mL}$ normal saline intravenously over $10-15 \mathrm{~min} .10 \mathrm{ml}$ of $2 \%$ lignocaine solution was given via nebulization as topical anesthesia. Patients were observed for any adverse effects. After preparation of patients, nasotracheal tube was inserted through the nostril into the oropharynx. A well-lubricated fiberoptic bronchoscope was passed through the tube and manipulated to identify the epiglottis and cords. The bronchoscope was advanced into the trachea to the level of carina and the tube was threaded over it. 


\section{Original Research}

The degree of sedation was classified by an experienced observer according to the Ramsay Sedation Score.

Mean arterial pressure (MAP), heart rate (HR) and pulse oxygen saturation $\left(\mathrm{SpO}_{2}\right)$ were monitored. Hypoxemic episodes were defined as $\mathrm{SpO}_{2}<90 \%$ and lasting $>10$ sec. Apnea was defined as the absence of spontaneous respiration for $>15 \mathrm{sec}$. If hypoxemia or apnea occurred, spontaneous respiration was encouraged by tactile or vocal stimuli.

If hypotension occurred (MAP decreased $>30 \%$ of baseline), $6 \mathrm{mg}$ IV mephentermine was administered. If heart rate decreased to $<50$ beats/min, $0.6 \mathrm{mg}$ atropine was given IV.

If patient was too uncooperative or restless, inj propofol was used as a rescue drug to facilitate sedation and smooth intubation.

\section{Statistical Analysis:}

The sample size was calculated to be $\mathrm{N}=40$ based on the following considerations: $95 \%$ confidence level and $80 \%$ power of the study. Statistical analysis was performed using unpaired T-test for normally distributed parametric data. A $\mathrm{p}<0.05$ was considered statistically significant.

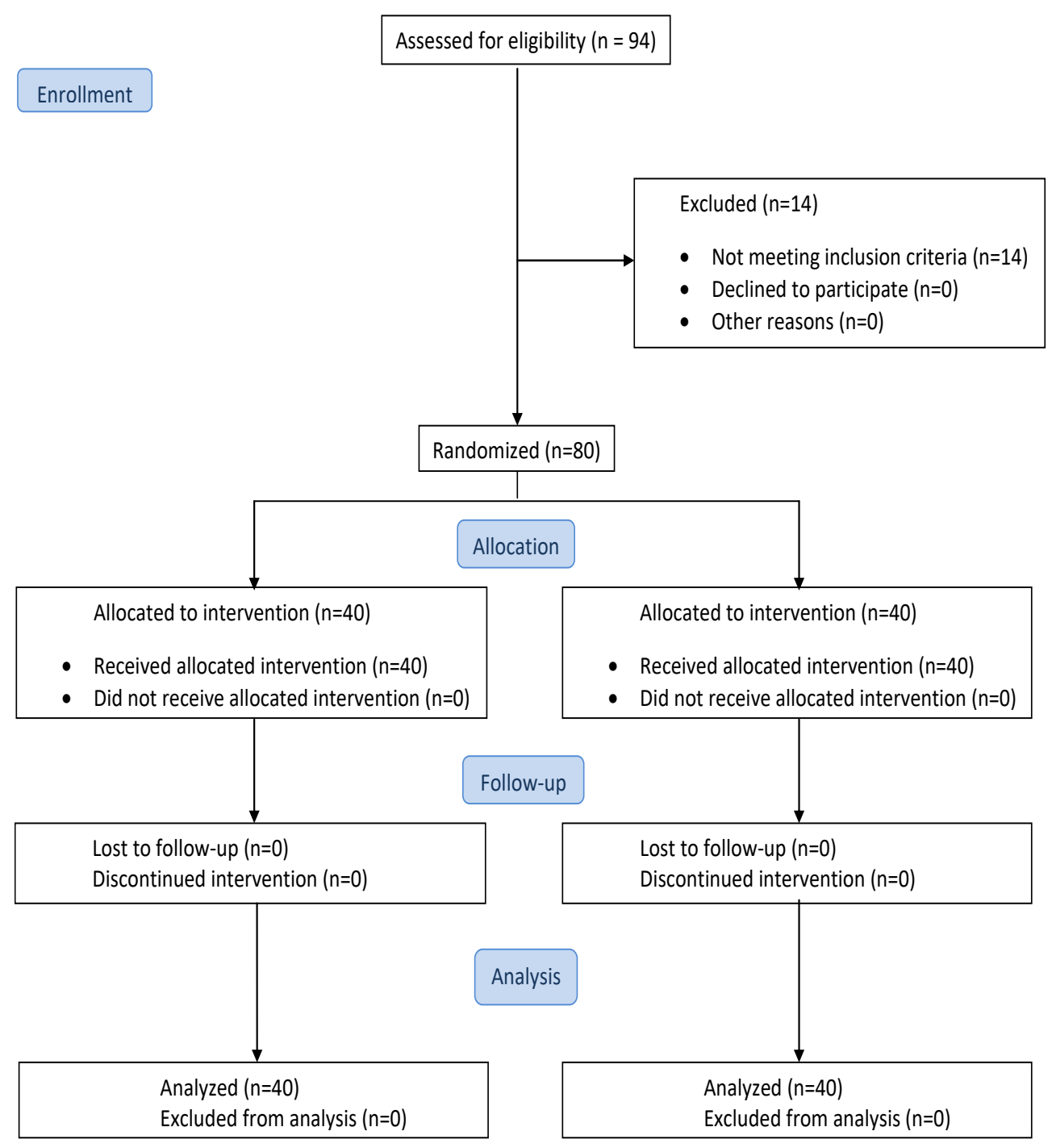

Figure 1: Flow chart of the study 


\section{RESULTS}

The demographic data, e.g. mean age, height, weight and BMI of the patients in both groups were statistically equivalent in both of the groups. In Group M1 36 (90\%) patients were males and in Group M2 38 (95\%) were males and $2(5 \%)$ were females (Table 1$)$.

Secondary objectives of the study including mouth opening $(p=0.372)$, Mallamptti scores 3 and $4(\mathrm{p}=0.824)$, and the frequency of comorbid conditions, hypertension or diabetes
( $\mathrm{p}=0.696)$ were equivalent in both groups, as shown in Table 2.

Ramsay Sedation Scores were statistically significantly better in Group M2, in that 23 $(57.5 \%)$ patients scored 2 and 3, compared to 11 $(27.5 \%)$ patients in Group M1 $(p=0.006)$ as shown in Table 2.

Majority of the patients in Group M1 scored 1 [29 (72.5\%)] as compared to Group M2 [17 $(42.5 \%)](\mathrm{p}=0.006)$ as shown in Table 2 and Figure 2

Table 1: Demographic parameters

\begin{tabular}{lccc}
\multicolumn{1}{c}{ Parameter } & Group M1 & Group M2 & p-value \\
Mean Age & $28.70 \pm 8.936$ & $29.30 \pm 8.718$ & 0.762 \\
\hline Gender M/F & $36 / 4$ & $38 / 2$ & \\
\hline Weight & $67.13 \pm 11.170$ & $65.08 \pm 11.079$ & 0.412 \\
\hline Height & $164.18 \pm 9.721$ & $163.80 \pm 8.389$ & 0.854 \\
\hline BMI & $24.959 \pm 4.072$ & $24.437 \pm 4.952$ & 0.304 \\
\hline \multirow{2}{*}{ ASA Grade } & Grade I = 30 & Grade I = 32 & 0.299
\end{tabular}

Table 2: Results of secondary objectives in Groups M1 and M2

\begin{tabular}{|c|c|c|c|}
\hline Parameter & Group M1 $(n=40)$ & Group M2 $(n=40)$ & p-value \\
\hline \multicolumn{4}{|l|}{ Mouth Opening } \\
\hline 1 finger & $19(47.5 \%)$ & $15(37.5 \%)$ & \multirow{2}{*}{0.372} \\
\hline 2 fingers & $21(52.5 \%)$ & $25(62.5 \%)$ & \\
\hline \multicolumn{4}{|l|}{ MPG } \\
\hline 3 & $22(55 \%)$ & $15(57.5 \%)$ & \multirow{2}{*}{0.824} \\
\hline 4 & $18(45 \%)$ & $25(42.5 \%)$ & \\
\hline \multicolumn{4}{|l|}{ Comorbidity } \\
\hline Hypertension & $2(5 \%)$ & $4(10 \%)$ & \multirow{2}{*}{0.696} \\
\hline Diabetes & $2(5 \%)$ & $2(5 \%)$ & \\
\hline \multicolumn{4}{|c|}{ Ramsay Sedation Score } \\
\hline 1 & 29 & 17 & \multirow{3}{*}{0.006} \\
\hline 2 & 8 & 14 & \\
\hline 3 & 3 & 9 & \\
\hline
\end{tabular}




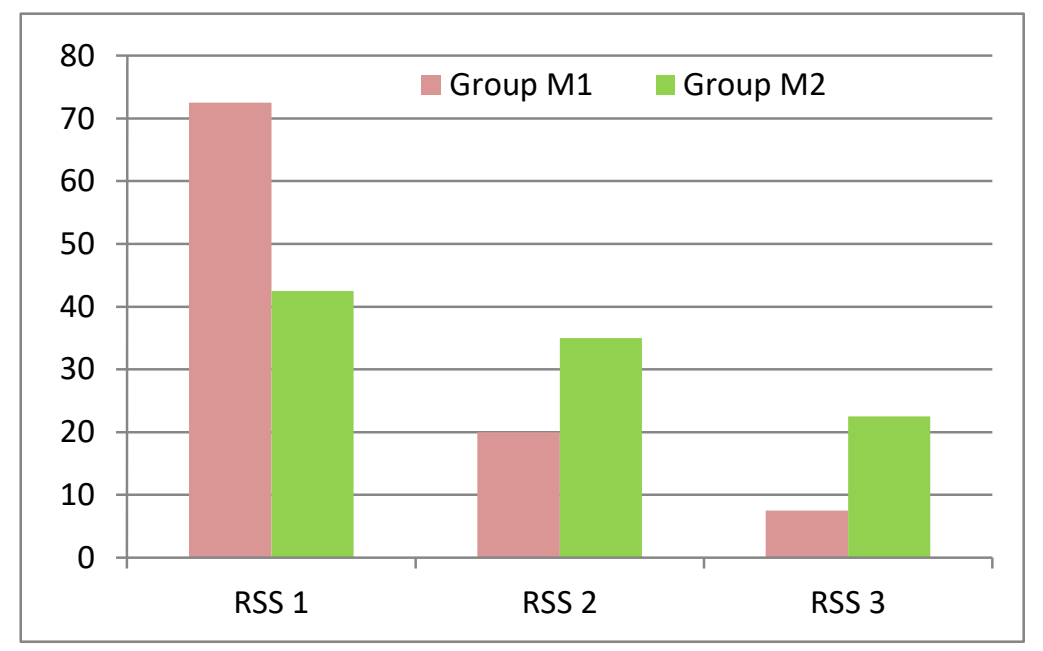

Figure 2: Ramsay sedation score
Hemodynamic parameters e.g. $\mathrm{HR}, \mathrm{MAP}, \mathrm{EtCO}_{2}, \mathrm{SpO}$, Peak Airway Pressure and respiratory rate $(\mathrm{RR})$ were measured preoperatively, after $\mathrm{MgSO}_{4}$ administration and after AFOI. Data are given in Table 3. The differences in between both groups was statistically not significant. MAP and HR in both groups has been graphically depicted in Figure 3

Table 3: Summary of vital signs (Data given as Mean \pm SD)

\begin{tabular}{|c|c|c|c|c|}
\hline Parameter & Group M1 $(n=40)$ & Group M2 ( $n=40)$ & t-value & p-value \\
\hline HR: Preoperative & $83.58 \pm 9.551$ & $81.20 \pm 12.934$ & 0.934 & 0.353 \\
\hline $\mathrm{HR}$ after $\mathrm{MgSO}_{4}$ administration & $86.28 \pm 10.466$ & $82.70 \pm 11.815$ & 1.432 & 0.156 \\
\hline HR after AFOI & $90.53 \pm 9.348$ & $85.95 \pm 10.919$ & 2.013 & 0.048 \\
\hline MAP; Preoperative & $91.45 \pm 12.850$ & $88.50 \pm 11.852$ & 1.067 & 0.289 \\
\hline MAP after $\mathrm{MgSO}_{4}$ administration & $86.70 \pm 9.296$ & $83.15 \pm 8.601$ & 1.773 & 0.080 \\
\hline MAP after AFOI & $89.25 \pm 6.126$ & $84.88 \pm 11.872$ & 2.071 & 0.042 \\
\hline $\mathrm{EtCO}_{2} ;$ Preoperative & $35.50 \pm 3.226$ & $34.45 \pm 3.351$ & 1.428 & 0.157 \\
\hline $\mathrm{EtCO}_{2}$ after $\mathrm{MgSO}_{4}$ administration & $35.45 \pm 3.129$ & $35.85 \pm 3.134$ & -0.571 & 0.570 \\
\hline $\mathrm{EtCO}_{2}$ after $\mathrm{AFOI}$ & $35.20 \pm 3.098$ & $34.90 \pm 3.053$ & 0.436 & 0.664 \\
\hline $\mathrm{SpO}_{2} ;$ Preoperative & $98.10 \pm 1.516$ & $97.60 \pm 1.516$ & 1.475 & 0.144 \\
\hline $\mathrm{SpO}_{2}$ after $\mathrm{MgSO}_{4}$ administration & $97.40 \pm 1.722$ & $97.80 \pm 1.588$ & -1.080 & 0.283 \\
\hline $\mathrm{SpO}_{2}$ after $\mathrm{AFOI}$ & $97.93 \pm 1.289$ & $97.90 \pm 1.499$ & 0.080 & 0.936 \\
\hline Peak Airway Pressure; Preop & $16.50 \pm 2.124$ & $16.98 \pm 1.941$ & -1.044 & 0.300 \\
\hline Peak Airway Pressure after $\mathrm{MgSO}_{4}$ & $16.65 \pm 2.143$ & $17.23 \pm 2.044$ & -1.228 & 0.223 \\
\hline Peak Airway Pressure after AFOI & $17.43 \pm 1.824$ & $17.15 \pm 1.942$ & 0.653 & 0.516 \\
\hline RR; Preoperative & $17.28 \pm 2.025$ & $17.08 \pm 1.966$ & 0.448 & 0.655 \\
\hline $\mathrm{RR}$ after $\mathrm{MgSO}_{4}$ administration & $16.85 \pm 1.902$ & $17.35 \pm 1.916$ & -1.171 & 0.245 \\
\hline RR after AFOI & $17.40 \pm 2.170$ & $17.20 \pm 1.884$ & 0.440 & 0.661 \\
\hline
\end{tabular}

$H R=$ Beats $/$ min $; M A P=m m H g ; E t C O_{2}=m m H g ;$ Peak Airway Pressure $=\mathrm{CmH}_{2} \mathrm{O} ; \mathrm{RR}=$ Breaths $/ \mathrm{min}$ 


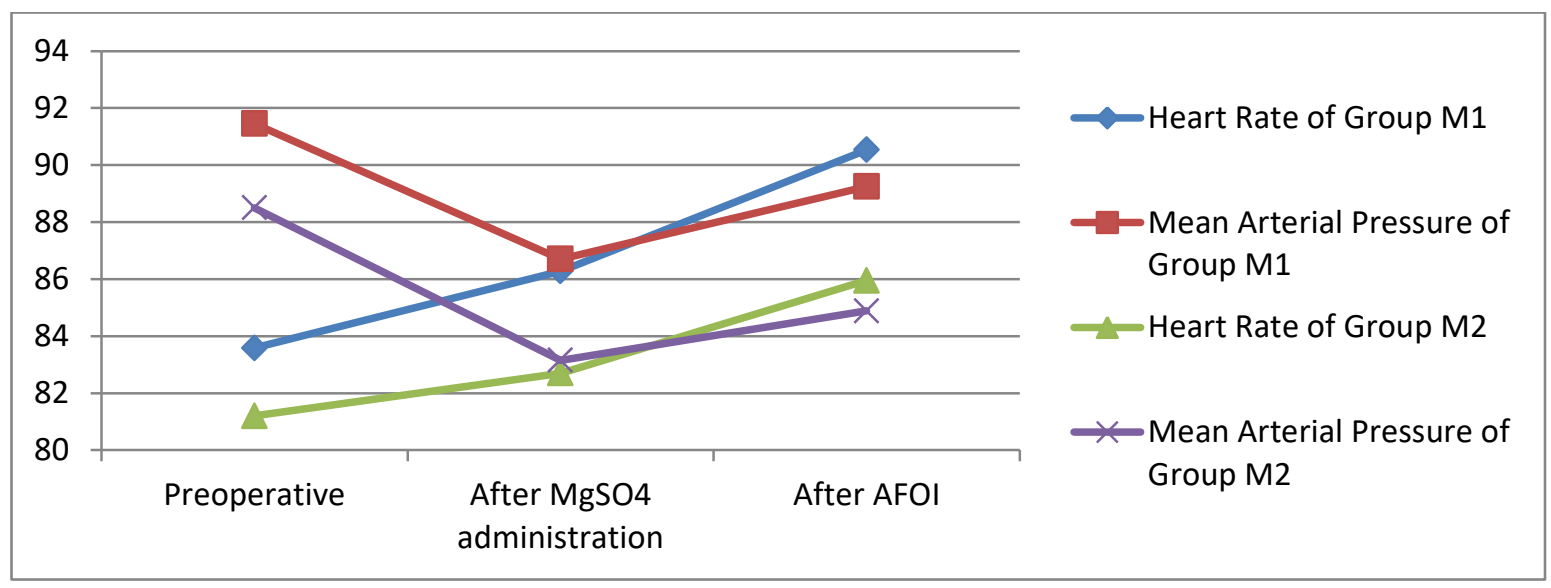

Figure: 3 Hemodynamic parameters for Group M1 and M2

\section{DISCUSSION}

AFI is the gold standard for management of difficult airway. It can be an unpleasant experience for the patient even with meticulous application of local anesthetic. Conscious sedation is desirable not only to make the procedure more tolerable for patients but also to ensure optimal intubation conditions, particularly in the presence of abnormal laryngeal anatomy and physiology. A major challenge during AFI is to provide adequate sedation while maintaining patent airway and spontaneous ventilation. Deep sedation can result in loss of airway with serious consequences. We successfully used this drug foe adequate sedation for AFI in our patients. It may be used as a single IV drug with upper airway nebulization with lignocaine solution or with other sedatives, where it would impart the advantage of reducing the doses of all sedative drugs.

Magnesium is the fourth most abundant cation in the body and the second most abundant intracellular cation. It acts as a natural antagonist to calcium ions regulating their access into the cell. It can be used to prevent and alleviate pain by acting as an antagonist at $\mathrm{N}$-methyl-D-aspartate receptors.

The study of Tramer et al. demonstrated the significance of magnesium as an adjuvant in post-operative analgesia. Patients receiving magnesium had a lower requirement of morphine and had comparatively less discomfort during first $48 \mathrm{~h}$ postoperatively than those receiving morphine alone. Multiple incidences of respiratory depression occurred in the group receiving morphine only versus none in the group given a regime of morphine and magnesium. ${ }^{5}$ Koinig et al. reported similar results, with a decreased requirement of intraoperative and post-operative analgesia. ${ }^{6}$

In the present study, lesser rise in heart rate and mean arterial pressure was noted in Group M2 as compared to Group M1 following AFI. Sedation provided by magnesium sulphate was more profound and suitable for AFI at a dose of $45 \mathrm{mg} / \mathrm{kg}$ as compared to the dose of $30 \mathrm{mg} / \mathrm{kg}$. Similar results were found in a study conducted by Panda et al. ${ }^{7}$

Magnesium is considered to be a muscle relaxant like agent. Neuromuscular transmission is impaired by diminution in the release of acetylcholine at motor nerve terminal. A clinical study demonstrated that a rapid infusion of $\mathrm{MgSO}_{4}(50 \mathrm{mg} / \mathrm{kg})$ can re-establish relevant degree of muscle paralysis in patients who have just recovered from non-depolarizing blocking agents. $^{8}$

In patients with tetanus $\mathrm{MgSO}_{4}$ infused at doses maintaining serum concentrations of 2-4 


\section{Original Research}

$\mathrm{mmol} / \mathrm{L}$ allowed good control of spasm and muscle rigidity.

Magnesium reduces the release of acetylcholine from motor nerve terminal, resulting in diminished excitability of the muscle fiber itself and decrease in the amplitude of the end plate potential. It therefore, potentiates the nondepolarizing neuromuscular blocking agents.

Magnesium impairs the release of catecholamine from the adrenal medulla and adrenergic nerve endings. It attenuates the vasopressor response to laryngoscopy and intubation.

Choi et al. concluded that IV magnesium sulphate reduced propofol infusion requirements. It may perhaps be related to the sedative effect of magnesium. Magnesium has been reported to induce general anesthesia and to potentiate the activity of local anesthetic agents. ${ }^{10}$ A narcotic state inhuman being undergoing surgical operations was achieved in a study by Peck and Meltzer who reported three patients undergoing hernioplasty under general anesthesia by $\mathrm{MgSO}_{4}$ infusion. ${ }^{11}$
$\mathrm{MgSO}_{4}$ has added a new dimension to the administration of anesthesia, whether it is GA or regional or local anesthesia. The anesthesiologists can now enjoy more flexibility in the show of their art.

\section{CONCLUSION}

The use of magnesium sulphate as sedative produces adequate sedation scores in patients with maxillofacial trauma undergoing awake fiberoptic intubation, but the scores were found to be significantly higher with $45 \mathrm{mg} / \mathrm{kg}$ use as compared to $30 \mathrm{mg} / \mathrm{kg}$. On comparing the hemodynamic parameters before and after intubation it was noted that there was more blunting of hemodynamic response with 45 $\mathrm{mg} / \mathrm{kg} \mathrm{MgSO}_{4}$. No respiratory depression was observed in either groups; both had preserved patency of airway. Overall $\mathrm{MgSO}_{4}$ is a safe and effective drug to provide sedation during awake fiberoptic intubation with minimal side effects.

Conflict of interest: None declared by the authors.

Authors' contribution:

KM - Manuscript editing

RM - Concept of study, statistical analysis

AS, DKS - Conduct of study 


\section{Comparison of two doses of magnesium sulphate as sedative}

\section{REFERENCES}

1. Collins SR, Blank RS. Fiberoptic Intubation: An Overview and Update. Respir Care. 2014 Jun;59(6):865-78; discussion 87880. [PubMed] DOl: 10.4187/respcare.03012

2. Khaskheli MS, Tabassum R, Awan $\mathrm{AH}$. Effectiveness of magnesium sulphate in acute asthma: a retrospective study. Anaesth Pain Intensive Care. 2017;21(4):458-62. [Free full text]

3. Do SH. Magnesium: a versatile drug for anesthesiologists. Korean $\mathrm{J}$ Anesthesiol. 2013;65(1):4-8. [PubMed] $\mathrm{DOI}$ 10.4097/kjae.2013.65.1.4

4. Bansal K, Santpur MU, Garg U, Goel K, Vijay D, Tatineni Bansal. Effect of intravenous magnesium sulphate on hemodynamic response to pneumoperitoneum in laparoscopic cholecystectomy: A prospective, double blind study. Anaesth Pain Intensive Care. 2019;23(3):290-29 [Free full text] DOI: $10.35975 / a p i c . v 23 i 3.1138$

5. Tramer MR, Schneider J, Marti RA, Rifat K. Role of magnesium sulfate in postoperative analgesia. Anesthesiology. 1996;84(2):340-7. [PubMed] DOI: 10.1097/00000542199602000-00011

6. Koinig $\mathrm{H}$, Wallner $\mathrm{T}$, Marhofer $\mathrm{P}$, Andel $\mathrm{H}$, Hörauf $\mathrm{K}$, Mayer $\mathrm{N}$. Magnesium sulfate reduces intraand postoperative analgesic requirements. Anesth Analg. 1998:87:206-10. [PubMed] DOI: 10.1097/00000539-199807000$\underline{00042}$

7. Panda NB1, Bharti N, Prasad S. Minimal effective dose of magnesium sulfate for attenuation of intubation response in hypertensive patients. J Clin Anesth. 2013 Mar;25(2):92-7. [PubMed] DOl: 10.1016/j.jclinane.2012.06.016

8. Hans GA, Bosenge $B$, Bonhomme VL, Brichant JF, Venneman IM, Hans PC. Intravenous magnesium re-establishes neuromuscular block after spontaneous recovery from an intubating dose of rocuronium: A randomised controlled trial. Eur $\mathrm{J}$
Anaesthesiol. $\quad$ 2012;29(2):95-9.

[PubMed] DOI:

10.1097/EJA.0b013e32834e13a6

9. Rodrigo C, Fernando D, Rajapakse S. Pharmacological management of tetanus: an evidence-based review. Crit Care. 2014;18(2):217. [PubMed] DOI: $\underline{10.1186 / \mathrm{cc} 13797}$

10. Choi JC, Yoon KB, Um DJ, Kim C, Kim JS, Lee SG. Intravenous magnesium sulfate administration reduces propofol infusion requirements during maintenance of propofol-N2o anesthesia: part i: comparing propofol requirements according to hemodynamic responses: part ii: comparing bispectral index in control and magnesium groups. Anesthesiology. 2002;97(5):113741. [PubMed] DOI: 10.1097/00000542-20021100000017

11. Peck $\mathrm{CH}$, Meltzer SJ. Anaesthesia in human beings by I.V. injection of MgSO4. J Am Med Assoc. 1916:601:1131-3 